\title{
Neurosurgical and Intensive Care Management of Traumatic Brain Injury
}

\author{
Martin Seule, MD ${ }^{1}$ Thomas Brunner, MD ${ }^{2}$ Alexander Mack, MD ${ }^{1}$ Gerhard Hildebrandt, MD ${ }^{1}$ \\ Jean-Yves Fournier, MD ${ }^{1}$
}

${ }^{1}$ Department of Neurosurgery, Kantonsspital St. Gallen,

St. Gallen, Switzerland

2 Surgical Intensive Care Unit, Kantonsspital St. Gallen,

St. Gallen, Switzerland

Facial Plast Surg 2015;31:325-331.

\begin{abstract}
Address for correspondence Martin Seule, MD, Department of Neurosurgery, Kantonsspital St. Gallen, Rorschacherstrasse 95, CH-9007, St. Gallen, Switzerland (e-mail: martin.seule@kssg.ch).
\end{abstract}

Abstract
Keywords
- traumatic brain injury
- neurosurgery
- neurocritical care

Optimal management of patients with traumatic brain injury (TBI) remains a challenge, despite significant improvements in pathophysiologic understanding and treatment strategies in recent decades. Because primary brain injury sustained at the time of trauma is irreversible, the TBI management mainly aims for early detection and treatment of secondary brain injury such as space-occupying intracerebral hematomas and brain edema. Prevention of secondary brain injury requires a high standard of care and understanding of both medical and surgical treatment modalities. This review focuses on practical recommendations for neurosurgical and intensive care management in patients with severe TBI.

Traumatic brain injury (TBI) is the leading cause of death and disability in young adults. ${ }^{1}$ Population-based studies have shown mortality rates up to $45 \%$ and significant neurologic disability in almost half of the surviving patients. ${ }^{2,3}$ Furthermore, the long-term effects of neuropsychological dysfunction may create significant difficulties in social reintegration, independence, and employment. ${ }^{4}$

Facial fractures have long been suggested to provide a cushion zone to the cranium and therefore may limit the extent of severe brain injury. ${ }^{5}$ However, more recent studies showed that the impact forces transmitted to the head are often associated with brain injury. ${ }^{6,7}$ The incidence of TBI in patients with maxillofacial fractures is approximately $25 \%{ }^{8}$ Therefore, facial bone fractures may be considered as highly suspicious for associated brain injury.

TBI may result in various injuries, including skull fractures, diffuse axonal injury, and cerebrovascular injuries. Primary brain injury sustained at the time of trauma is irreversible and remains the most important determinant of neurologic outcome. Therefore, the TBI management focuses on preventing secondary brain injury in the hours and days following trauma, which may have intracranial (e.g., hematoma, brain edema) as well as extracranial causes (e.g., hypoxia, hypotension).
The severity of brain injury correlates closely with neurologic outcome and is classified by the initial postresuscitation Glasgow Coma Scale (GCS, - Table 1) and further by findings on computed tomographic (CT) imaging. ${ }^{9,10}$ Severe TBI is defined as GCS 8 or less and associated with poor, but in most cases not hopeless, prognosis. The overall severity of patients with multiple injuries can be assessed using the Injury Severity Score (ISS) according to different anatomical body regions, where an ISS greater than 14 is generally accepted as a definition of a patient with major trauma. ${ }^{11}$

Noncontrast CT scan is the diagnostic method of choice in the acute phase after TBI. The presence and extend of mass lesions and their consequences, leading to high intracranial pressure (ICP), should be considered. However, a direct correlation between CT imaging and high ICP is lacking. ${ }^{12}$ Therefore, ICP monitoring using minimally invasive brain tissue probes should always be considered in unconscious and/or sedated patients with TBI.

The need for surgical intervention is based on both the patient's neurologic condition and findings on CT imaging. ${ }^{13-15}$ The most important concern in patients with TBI is the development of high ICP due to a pathophysiologic cascade of intra- and extracellular derangements leading to secondary brain injury. ${ }^{16}$ Recently, it has been shown that
DOI http://dx.doi.org/ 10.1055/s-0035-1562884. ISSN 0736-6825. 
Table 1 Classification of severity of traumatic brain injury

\begin{tabular}{|l|l|}
\hline Severity & Glasgow Coma Scale \\
\hline Mild & $13-15$ \\
\hline Moderate & $9-12$ \\
\hline Severe & $3-8$ \\
\hline
\end{tabular}

Note: Severity of traumatic brain injury is classified into mild, moderate, and severe according to the Glasgow Coma Scale.

multimodal neuromonitoring using brain tissue oxygen tension and microdialysis monitoring is more effective in detecting secondary brain injury than ICP monitoring alone. ${ }^{17}$ Multimodal neuromonitoring may further allow monitoring the effects of medical and/or surgical interventions aiming at ICP control.

\section{Surgical Issues and Considerations}

\section{Depressed Skull Fracture}

Depressed skull fractures are classified as either "closed" or "open," depending on the presence or absence of an overlying scalp laceration, respectively. An open fracture depressed greater than the thickness of the skull requires surgical repair and prophylactic antibiotics to prevent bacterial infection (-Fig. 1). ${ }^{18}$ Surgical objectives include (1) debridement of the contaminated bone fragments and soft tissue, (2) evacuation of intracranial hematoma and repair of a dural laceration if present, and (3) reconstruction of the skull. Observation can be considered for closed fractures depressed less than $1 \mathrm{~cm}$ without evidence of dural penetration and cerebrospinal fluid leak.

\section{Frontal Sinus Fracture}

Fractures of the frontal sinus involve the (1) anterior table, (2) posterior table, or (3) both. Management strategies include prevention of short- and long-term complications, correction of aesthetic deformity, and reestablishment of normal sinus function. ${ }^{19}$ In particular, posterior table fractures are associated with a high risk of cerebrospinal fluid (CSF) leak, meningitis, and mucocele formation. Therefore, surgical repair (frontal sinus obliteration or cranialization) can be considered for significant disruption of the posterior table (displacement $>1$ table width), CSF leak, and nasofrontal tract obstruction. ${ }^{19,20}$ Frontal sinus obliteration is performed in the presence of significant posterior table displacement and nasofrontal tract obstruction. Frontal sinus cranialization should be considered with CSF leak and/or severe comminution of the posterior table. The timing of surgery mainly depends on the patients' condition, often requiring a staged procedure with wound debridement in the acute phase and surgery for frontal sinus fracture in a second step. There is no definitive evidence regarding prophylactic antibiotic use. Observation can be considered for anterior table fractures as well as posterior table fractures displaced less than 1 table width and no evidence of CSF leak. In these cases, clinical and radiologic follow-up should be performed to rule out longterm complications (mucocele formation, meningitis, brain abscess).

\section{Epidural Hematoma}

Epidural hematomas (EDHs) are mainly caused by an arterial bleeding of dural vessels, typically affecting the middle meningeal artery, and are associated with temporoparietal skull fractures. The classic clinical presentation includes a brief loss of consciousness followed by a lucid interval for several hours before neurologic deterioration occurs. Large EDHs may cause contralateral hemiparesis, impaired consciousness, and ipsilateral pupillary dilatation. The CT appearance of EDHs is a high-density biconvex shape adjacent to the skull (-Fig. 2). Surgical intervention is recommended in cases of a hematoma volume greater than $30 \mathrm{~cm}^{3}$, independent of the patients' neurologic condition. ${ }^{13} \mathrm{~A}$ frontotemporoparietal craniotomy is performed to gain sufficient access to middle meningeal vessels. The surgical objectives include (1) removal of the space-occupying hematoma and (2) control of the bleeding source. Rebleeding is prevented by placing tack-up sutures along the dura margin and central dura before replacing the bone flap. Evacuation of EDHs within a few hours after trauma is associated with a mortality rate of approximately $10 \%$. Although a burr-hole approach can be a

A
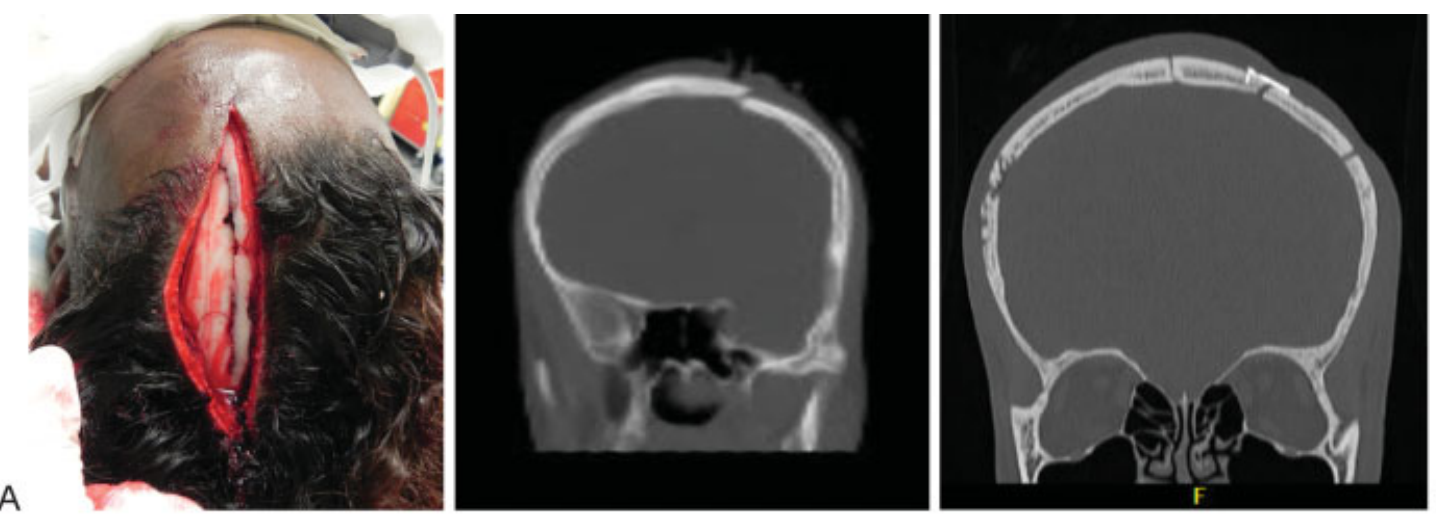

B,C

Fig. 1 (A) Depressed skull fracture with overlying scalp laceration after a bicycle accident (initial Glasgow Coma Scale [GCS] 14). (B and C) Coronal computed tomographic (CT) scan (bone window) before and after reconstruction of the skull. 
A
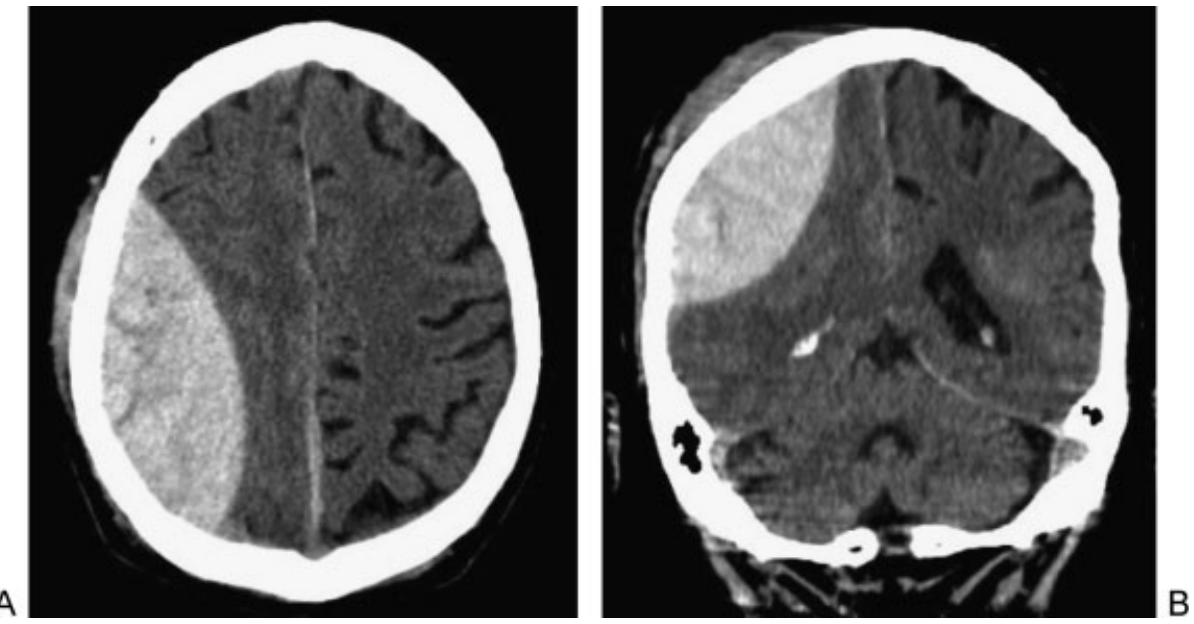

Fig. 2 Typical frontotemporoparietal epidural hematoma after a fall causing impaired consciousness (Glasgow Coma Scale [GCS] 12) and leftsided hemiparesis (axial [A] and coronal [B] computed tomographic [CT] scan; soft tissue window).

lifesaving measure, it may be insufficient to control the bleeding source. ${ }^{21}$ Observation can be considered in patients without significant neurologic deterioration (GCS $>8$, absent neurologic deficit) and CT findings (hematoma volume $<30$ $\mathrm{cm}^{3}$, maximum thickness $<15 \mathrm{~mm}$, and midline shift $<5$ $\mathrm{mm})$. Conservative management should always include close neurologic monitoring of the patient and follow-up CT scan within 6 to 8 hours.

\section{Acute Subdural Hematoma}

Acute subdural hematomas (aSDHs) commonly arise from blood accumulation around parenchymal lesions as well as disruption of surface or bridging veins. In contrast to EDHs, the impact of damage is usually much higher, associated with further underlying brain injury (e.g., intracerebral hematoma, contusion) and mortality rates up to $60 \%{ }^{22,23}$ Symptoms such as impaired consciousness and focal neurologic deficits occur due to the space-occupying effect with midline shift and possibly brain edema. On CT imaging, aSDHs present as a crescent mass of high density often associated with a midline shift and brain edema (-Fig. 3). Surgical intervention is recommended in aSAH with (1) thickness greater than $10 \mathrm{~mm}$ or midline shift greater than $5 \mathrm{~mm}$ independent of the patient's GCS, and (2) pupillary dilation and/or ICP greater than $20 \mathrm{~mm} \mathrm{Hg}$ even if the thickness is less than $10 \mathrm{~mm}$ and midline shift less than $5 \mathrm{~mm} .{ }^{14}$ Surgery should be performed in these cases as soon as possible. The subdural space is usually accessed through a large frontotemporoparietal craniotomy (so-called trauma flap) and wide dural incision. The surgical objectives include (1) removal of the hematoma, (2) control of bleeding points on the cortical surface, and (3) watertight closure of the dura. In case of significant brain edema, releasing dural incisions and duraplasty without replacing the bone flap may be performed (decompressive

A
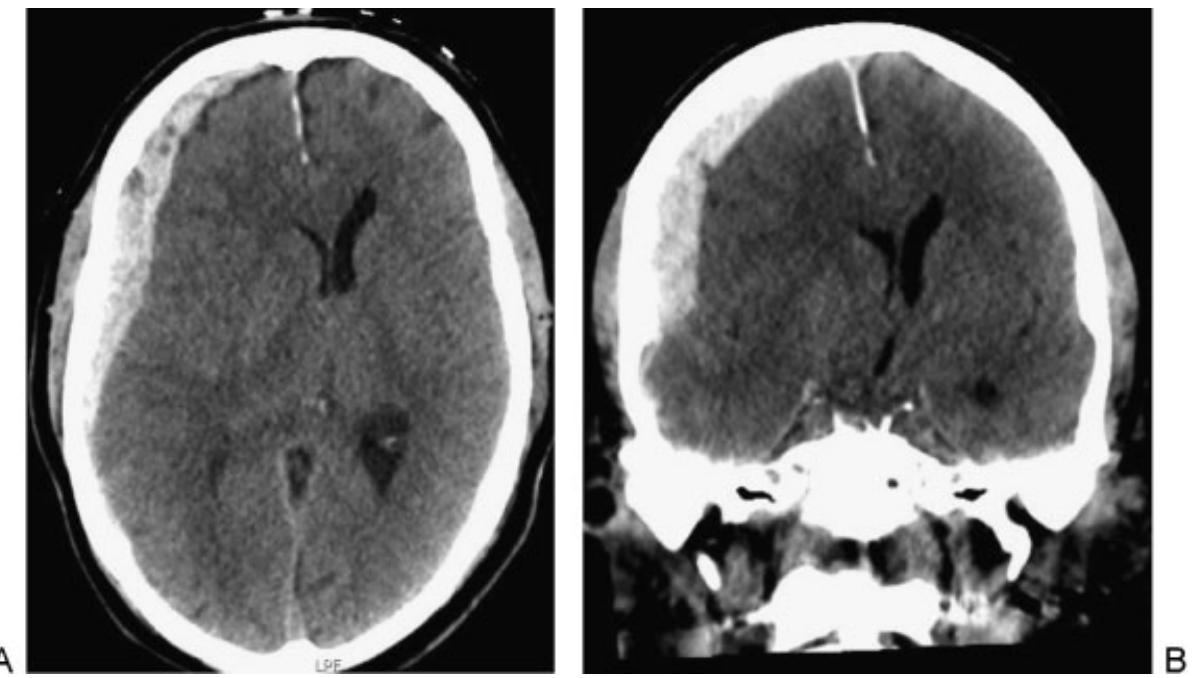

Fig. 3 Acute subdural hematoma after a fall (Glasgow Coma Scale [GCS] 8) causing a significant midline shift (axial [A] and coronal [B] computed tomographic $[\mathrm{CT}]$ scan; soft tissue window). 

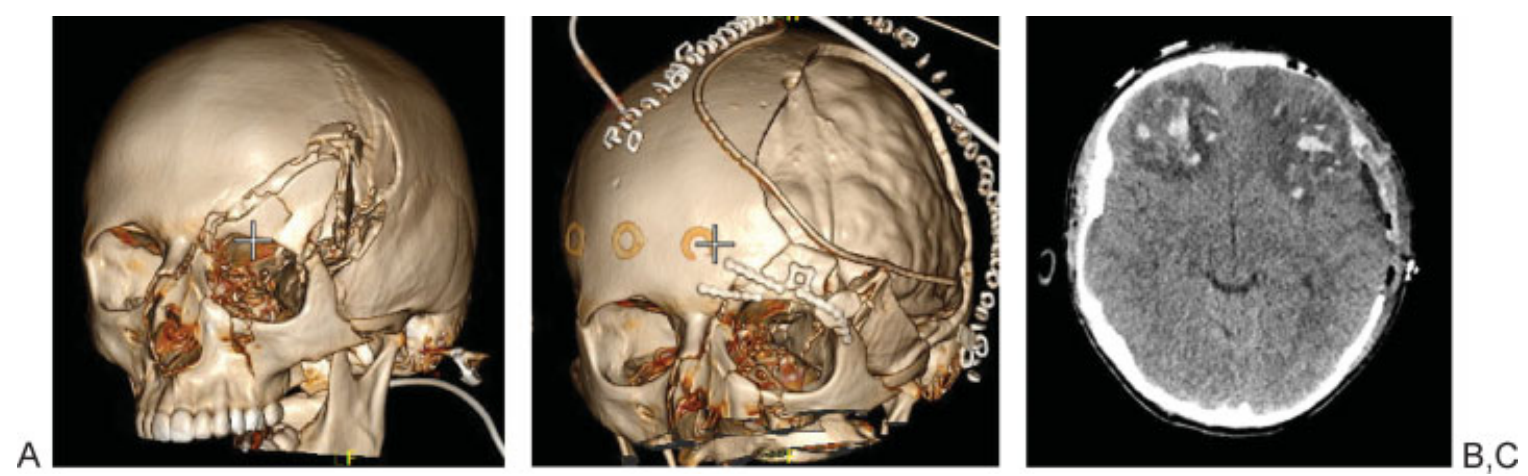

Fig. 4 (A) Combined skull and facial fractures after a high-velocity motor vehicle accident (Glasgow Coma Scale [GCS] 6). (B and C) Postoperative computed tomographic (CT) scan with reconstruction of the supraorbital rim and decompressive craniectomy due to severe bilateral frontobasal contusions causing intracranial hypertension.

hemicraniectomy). Conservative treatment can be considered in patients not meeting the aforementioned criteria for surgical intervention. It is important to note that ICP monitoring should always be performed in comatose and/or sedated patients with aSDH for early detection of secondary neurologic deterioration.

\section{Traumatic Parenchymal Lesions}

Traumatic parenchymal lesions are classified as focal (intracerebral hematoma, contusions) or diffuse injury (brain edema, diffuse axonal injury). In particular, high-energy trauma is often associated with a combination of both, which

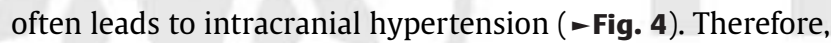
ICP monitoring should be considered in all comatose and/or sedated patients with traumatic parenchymal lesions. Surgical intervention should be considered in patients with secondary neurologic deterioration and/or ICP greater than $20 \mathrm{~mm} \mathrm{Hg} .{ }^{15}$ Hematomas and contusions may be evacuated following craniotomy. It has to be noted that only the central bulk of the hematoma is removed to spare potentially vital brain tissue. On the other hand, surgical treatment of diffuse brain injury with intracranial hypertension depends on large bony decompression of the swelling brain. Frontotemporoparietal or bifrontal decompressive craniectomy can be per- formed to effectively reduce elevated ICP. ${ }^{24}$ The effect of craniectomy on functional outcome in patients with therapy-refractory intracranial hypertension is currently being evaluated in a randomized clinical trial (RESCUEicp trial).

\section{Dissection of Cerebral Arteries}

Traumatic dissection of the internal carotid artery and/or vertebral artery may lead to cerebral infarction and consequently poor outcome especially in young patients. ${ }^{25}$ The most common causes are motor vehicle accidents with severe neck hyperextension and direct blows to the back of the head. Therefore, dissection of cerebral arteries should always be considered in patients with corresponding craniocervical injury. Early CT angiography should be performed to verify or rule out an intramural hematoma caused by transintimal extravasation of blood into the vessel wall. ${ }^{26}$ Symptoms may result from occlusion of the true vessel lumen and/or thromboembolism (-Fig. 5). ${ }^{27}$ The therapeutic goal is to prevent delayed ischemic events by starting medical therapy as soon as possible, with heparin acutely, followed by antiplatelet or anticoagulant drugs for 3 months. ${ }^{28}$ Arterial cerebral dissection presenting with subarachnoid hemorrhage or refractory to medical therapy may require neurosurgical or endovascular treatment.
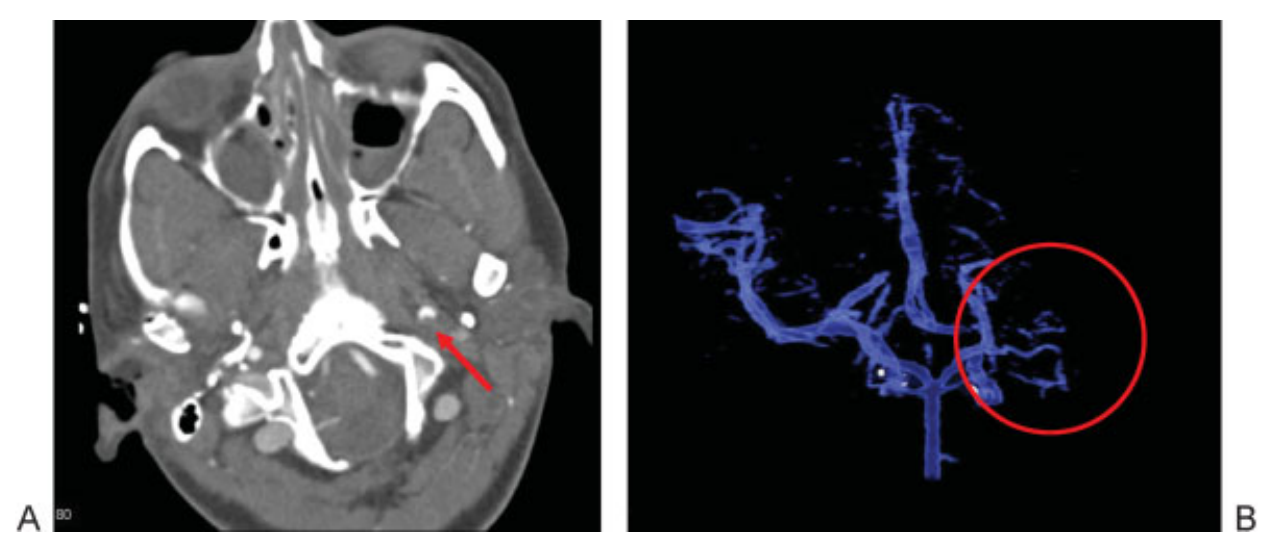

Fig. 5 Computed tomographic (CT) angiography showing intramural hematoma of the left extracranial internal carotid artery (arrow) after a motor vehicle accident (A) leading to thromboembolic occlusion of the middle cerebral artery and consecutive stroke (B). 


\section{Prevention of Secondary Brain Injury}

TBI patients should be managed according to a protocol including the Advanced Trauma Life Support and Brain Trauma Foundation Guidelines. ${ }^{29,30}$ The expected benefits include shorter length of hospital stay and improved neurologic outcome. ${ }^{31,32}$ After initial resuscitation, diagnostic procedures, and damage control surgery, patients are transferred to an intensive care unit. The main goal of intensive care management is prevention of secondary brain injury by optimizing cerebral perfusion, oxygenation, nutritional supply, and homeostasis.

Intracranial hypertension is a common problem after severe TBI and occurs when the limits of cerebral volume regulation are reached. The Monroe-Kellie doctrine states that the sum of intracranial volumes (brain parenchyma, cerebral blood volume [CBV], cerebrospinal fluid) is constant within the rigid skull, and that an increase in volume of one compartment must be offset by a decrease in volume of another. ${ }^{33}$ However, continuing volume expansion due to brain edema or increasing intracerebral hematoma may result in elevated ICP ( $>20 \mathrm{~mm} \mathrm{Hg}$ ), which should be treated aggressively.

\section{Multimodal Neuromonitoring}

In recent years, multimodal neuromonitoring has gained an important role to provide best medical care tailored to the patient's condition. Monitoring methods include imaging studies (e.g., perfusion CT) as well as minimal-invasive brain tissue probes for bedside monitoring of cerebral hemodynamics and oxygenation (e.g., thermal diffusion probe, brain tissue oxygen tension probe, and microdialysis probe). Bedside neuromonitoring allows for early detection of secondary neurologic deterioration and to guide medical and surgical treatment modalities. Numerous studies have shown that TBI patients may benefit from multimodal neuromonitoring if managed according to standardized treatment protocols. ${ }^{34-36}$ However, a thorough understanding of the underlying pathophysiology is mandatory to individualize neurointensive care management.

\section{Sedation and Analgesia}

Sedation is one of the mainstays in early TBI management. The main effect is a decrease in both cerebral metabolic rate and cerebral oxygen consumption. Because of moderate cerebral vasoconstriction, lowering of cerebral blood volume and consequently ICP is achieved. ${ }^{37,38}$ On the other hand, sedation bears the risk of affecting hemodynamics, mainly hypotension, and complicates the clinical assessment of the patient. In deep sedation continuous electroencephalographic (EEG) monitoring should be used to assess the level of sedation. Neuromuscular blockade may be used to facilitate mechanical ventilation or minimizing coughing. ${ }^{39}$ Most commonly used are benzodiazepines, propofol, and barbiturates. Analgesia is provided by opioids and peripheral acting analgesics.

\section{Management of Intracranial Pressure and Cerebral Perfusion Pressure}

Intracranial pressure (ICP) and cerebral perfusion pressure (CPP) management according to a protocol is mandatory in all comatose and/or sedated patients with TBI. CPP is calculated by the difference between mean arterial pressure (MAP) and $\mathrm{ICP}(\mathrm{CPP}=\mathrm{MAP}-\mathrm{ICP})$. As the volume inside the rigid skull is fixed, space-occupying lesions may lead to raised ICP due to the Monro-Kellie doctrine as mentioned earlier. ICP greater than $20 \mathrm{~mm} \mathrm{Hg}$ is an independent risk factor of poor outcome and should be treated aggressively. ${ }^{40,41}$ Cerebral hypoperfusion is the most important cause of secondary brain injury; therefore, providing adequate CPP is crucial. According to Brain Trauma Foundation Guidelines, a CPP of 50 to $70 \mathrm{~mm} \mathrm{Hg}$ is recommended. ${ }^{42}$ Several treatment strategies exist to control ICP and CPP, including reduction in cerebral metabolism using sedation, induced hyperventilation, hyperosmolar therapy, hypothermia, and surgical approaches. External ventricular drainage is the easiest surgical procedure to reduce intracranial volume. A lumbar puncture is contraindicated due to the risk of brainstem herniation. Decompressive hemicraniectomy as mentioned earlier may serve as an ultima ratio therapy in patients with therapy-refractory high ICP.

\section{Hyperventilation}

Hyperventilation causes cerebral vasoconstriction reducing cerebral blood volume and ICP, but reduction in cerebral blood flow could be detrimental because brain tissue is at risk for ischemia. ${ }^{43}$ If hyperventilation is applied, extended neuromonitoring should be installed to measure cerebral hemodynamics and oxygenation ${ }^{44}$.

\section{Hyperosmolar Therapy}

Hyperosmolar therapy with mannitol or hypertonic saline is an important medical treatment option to reduce ICP. Mannitol establishes an osmotic gradient between plasma and brain cells, reducing cerebral edema by drawing water into the vascular system. Hypertonic saline produces a reduction in cerebral edema by moving water out of the brain and thus resulting in decreased ICP. ${ }^{45}$

\section{Mild Hypothermia}

Mild hypothermia $\left(33-35^{\circ} \mathrm{C}\right)$ has shown a reduction in ICP and improved outcome in patients with TBI. ${ }^{46}$ There is evidence that proactive management of the side effects of hypothermia (e.g., coagulopathy, electrolyte disorders, sepsis) leads to improved outcome. ${ }^{47}$ Hypothermia is part of many algorithms targeting patients with uncontrollable intracranial hypertension, although it is still considered experimental. An ongoing study may answer the remaining questions on hypothermia in TBI (Eurotherm3235 Trial).

\section{Respiratory Care}

Patients with severe head injury require a secure airway and mechanical ventilation to maintain arterial oxygen tension greater than $13 \mathrm{kPa}$ and arterial carbon dioxide tension between 4.5 and $5.0 \mathrm{kPa}$. Hypocapnia should be avoided due to cerebral vasoconstriction and its detrimental effect on CBF. Hypercapnia may raise ICP due to cerebral vasodilation $^{37}$. 


\section{Hemodynamics}

Intravascular volume should be maintained using isotonic crystalloids and colloids targeting euvolemia and hemoglobin levels between 70 and $100 \mathrm{~g} / \mathrm{L}$. Vasoactive drugs are frequently needed to maintain adequate MAP and CPP. Hypotension causes a reduction in cerebral blood flow and may result in cerebral hypoperfusion and ischemia. ${ }^{48}$ Hypertension may exacerbate vasogenic edema with increased ICP. ${ }^{49}$

\section{Nutritional Support and Glycemic Control}

Early nutritional support is recommended reducing gastric stress ulcera, enhancing immunologic function, and minimizing the risk of hypoglycemia. ${ }^{50}$ Laxatives and prokinetics should be used for stool regulation and reducing intrabdominal pressure. Maintaining glucose levels between 5 and 10 $\mathrm{mmol} / \mathrm{L}$ is adequate. Hyperglycemia is associated with worse neurologic outcome, whereas hypoglycemia may have even worse effects. $^{51}$

\section{Coagulation, Deep Venous Thrombosis Prophylaxis}

Aggressive management of coagulation disorders is mandatory in the initial resuscitation phase, aiming for normalization of coagulation parameters. Thrombosis prophylaxis with unfractionated heparin or low-molecular-weight heparin may be started in the following 48 to 72 hours after trauma. ${ }^{52}$ Up to this point, mechanical devices should be installed such as compression stockings, sequential compression devices, or vena cava filters due to other diseases.

\section{Conclusion}

Optimal treatment of patients with severe TBI requires integrated neurosurgical and intensive care management. Standardized treatment protocols including clear indications for surgical intervention and multimodal neuromonitoring may help manage the individual patient and improve outcome. However, a thorough knowledge of the pathophysiology underlying brain injury is required, in particular because of increasing complexity of management strategies.

\section{References}

1 Maas AI, Stocchetti N, Bullock R. Moderate and severe traumatic brain injury in adults. Lancet Neurol 2008;7(8):728-741

2 von Elm E, Osterwalder JJ, Graber C, et al. Severe traumatic brain injury in Switzerland-feasibility and first results of a cohort study. Swiss Med Wkly 2008;138(23-24):327-334

3 Murray GD, Teasdale GM, Braakman R, et al. The European Brain Injury Consortium survey of head injuries. Acta Neurochir (Wien) 1999;141(3):223-236

4 Gautschi OP, Huser MC, Smoll NR, et al. Long-term neurological and neuropsychological outcome in patients with severe traumatic brain injury. Clin Neurol Neurosurg 2013;115(12): $2482-2488$

5 Lee KF, Wagner LK, Lee YE, Suh JH, Lee SR. The impact-absorbing effects of facial fractures in closed-head injuries. An analysis of 210 patients. J Neurosurg 1987;66(4):542-547

6 Keenan HT, Brundage SI, Thompson DC, Maier RV, Rivara FP. Does the face protect the brain? A case-control study of traumatic brain injury and facial fractures. Arch Surg 1999;134(1):14-17
7 Martin RC II, Spain DA, Richardson JD. Do facial fractures protect the brain or are they a marker for severe head injury? Am Surg 2002;68(5):477-481

8 Zandi M, Seyed Hoseini SR. The relationship between head injury and facial trauma: a case-control study. Oral Maxillofac Surg 2013; 17(3):201-207

9 Marshall LF, Marshall SB, Klauber MR, et al. The diagnosis of head injury requires a classification based on computed axial tomography. J Neurotrauma 1992;9(Suppl 1):S287-S292

10 Teasdale G, Jennett B. Assessment of coma and impaired consciousness. A practical scale. Lancet 1974;2(7872):81-84

11 Baker SP, O'Neill B, Haddon W Jr, Long WB. The injury severity score: a method for describing patients with multiple injuries and evaluating emergency care. J Trauma 1974;14(3):187-196

12 Eisenberg HM, Gary HE Jr, Aldrich EF, et al. Initial CT findings in 753 patients with severe head injury. A report from the NIH Traumatic Coma Data Bank. J Neurosurg 1990;73(5):688-698

13 Bullock MR, Chesnut R, Ghajar J, et al; Surgical Management of Traumatic Brain Injury Author Group. Surgical management of acute epidural hematomas. Neurosurgery 2006;58(3, Suppl): S7-S15, discussion Si-iv

14 Bullock MR, Chesnut R, Ghajar J, et al; Surgical Management of Traumatic Brain Injury Author Group. Surgical management of acute subdural hematomas. Neurosurgery 2006;58(3, Suppl): S16-S24, discussion Si-iv

15 Bullock MR, Chesnut R, Ghajar J, et al; Surgical Management of Traumatic Brain Injury Author Group. Surgical management of traumatic parenchymal lesions. Neurosurgery 2006;58(3, Suppl): S25-S46, discussion Si-iv

16 Rosenfeld JV, Maas AI, Bragge P, Morganti-Kossmann MC, Manley GT, Gruen RL. Early management of severe traumatic brain injury. Lancet 2012;380(9847):1088-1098

17 Bouzat P, Marques-Vidal P, Zerlauth JB, et al. Accuracy of brain multimodal monitoring to detect cerebral hypoperfusion after traumatic brain injury*. Crit Care Med 2015;43(2):445-452

18 Bullock MR, Chesnut R, Ghajar J, et al; Surgical Management of Traumatic Brain Injury Author Group. Surgical management of depressed cranial fractures. Neurosurgery 2006;58(3, Suppl): S56-S60, discussion Si-iv

19 Strong EB. Frontal sinus fractures: current concepts. Craniomaxillofac Trauma Reconstr 2009;2(3):161-175

20 Castro B, Walcott BP, Redjal N, Coumans JV, Nahed BV. Cerebrospinal fluid fistula prevention and treatment following frontal sinus fractures: a review of initial management and outcomes. Neurosurg Focus 2012;32(6):E1

21 Nelson JA. Local skull trephination before transfer is associated with favorable outcomes in cerebral herniation from epidural hematoma. Acad Emerg Med 2011;18(1):78-85

22 Koç RK, Akdemir H, Oktem IS, Meral M, Menkü A. Acute subdural hematoma: outcome and outcome prediction. Neurosurg Rev 1997;20(4):239-244

23 Maxeiner H, Wolff M. Pure subdural hematomas: a postmortem analysis of their form and bleeding points. Neurosurgery 2007;61 (1, Suppl):267-272, discussion 272-273

24 Cooper DJ, Rosenfeld JV, Murray L, et al; DECRA Trial Investigators; Australian and New Zealand Intensive Care Society Clinical Trials Group. Decompressive craniectomy in diffuse traumatic brain injury. N Engl J Med 2011;364(16):1493-1502

25 Nedeltchev K, der Maur TA, Georgiadis D, et al. Ischaemic stroke in young adults: predictors of outcome and recurrence. J Neurol Neurosurg Psychiatry 2005;76(2):191-195

26 Eastman AL, Chason DP, Perez CL, McAnulty AL, Minei JP. Computed tomographic angiography for the diagnosis of blunt cervical vascular injury: is it ready for primetime? J Trauma 2006;60(5): 925-929, discussion 929

27 Seule MA, Gautschi OP, Fournier JY, Hildebrandt G. [Traumatic dissection of extra- and intradural arteries]. Praxis (Bern 1994) 2009;98(18):1021-1025 
28 Markus HS, Hayter E, Levi C, Feldman A, Venables G, Norris J; CADISS trial investigators. Antiplatelet treatment compared with anticoagulation treatment for cervical artery dissection (CADISS): a randomised trial. Lancet Neurol 2015;14(4):361-367

29 Ali J, Cohen R, Adam R, et al. Teaching effectiveness of the advanced trauma life support program as demonstrated by an objective structured clinical examination for practicing physicians. World J Surg 1996;20(8):1121-1125, discussion 1125-1126

30 Foundation BT. Guidelines for the management of severe traumatic brain injury. J Neurotrauma 2007;24(Suppl 1):S1-S106

31 Fakhry SM, Trask AL, Waller MA, Watts DD; IRTC Neurotrauma Task Force. Management of brain-injured patients by an evidencebased medicine protocol improves outcomes and decreases hospital charges. J Trauma 2004;56(3):492-499, discussion 499-500

32 Arabi YM, Haddad S, Tamim HM, et al. Mortality reduction after implementing a clinical practice guidelines-based management protocol for severe traumatic brain injury. J Crit Care 2010;25(2): 190-195

33 Mokri B. The Monro-Kellie hypothesis: applications in CSF volume depletion. Neurology 2001;56(12):1746-1748

34 Sanchez JJ, Bidot CJ, O'Phelan K, et al. Neuromonitoring with microdialysis in severe traumatic brain injury patients. Acta Neurochir Suppl (Wien) 2013;118:223-227

35 Purins K, Lewén A, Hillered L, Howells T, Enblad P. Brain tissue oxygenation and cerebral metabolic patterns in focal and diffuse traumatic brain injury. Front Neurol 2014;5:64

36 Prabhakar H, Sandhu K, Bhagat H, Durga P, Chawla R. Current concepts of optimal cerebral perfusion pressure in traumatic brain injury. J Anaesthesiol Clin Pharmacol 2014;30(3):318-327

37 Oertel M, Kelly DF, Lee JH, et al. Efficacy of hyperventilation, blood pressure elevation, and metabolic suppression therapy in controlling intracranial pressure after head injury. J Neurosurg 2002; 97(5):1045-1053

38 Kassell NF, Hitchon PW, Gerk MK, Sokoll MD, Hill TR. Alterations in cerebral blood flow, oxygen metabolism, and electrical activity produced by high dose sodium thiopental. Neurosurgery 1980 ; 7(6):598-603

39 Hsiang JK, Chesnut RM, Crisp CB, Klauber MR, Blunt BA, Marshall LF. Early, routine paralysis for intracranial pressure control in severe head injury: is it necessary? Crit Care Med 1994;22(9): 1471-1476

40 Bratton SL, Chestnut RM, Ghajar J, et al; Brain Trauma Foundation; American Association of Neurological Surgeons; Congress of Neurological Surgeons; Joint Section on Neurotrauma and Critical
Care, AANS/CNS. Guidelines for the management of severe traumatic brain injury. VIII. Intracranial pressure thresholds. J Neurotrauma 2007;24(Suppl 1):S55-S58

41 Czosnyka M, Balestreri M, Steiner L, et al. Age, intracranial pressure, autoregulation, and outcome after brain trauma. J Neurosurg 2005;102(3):450-454

42 Bratton SL, Chestnut RM, Ghajar J, et al; Brain Trauma Foundation; American Association of Neurological Surgeons; Congress of Neurological Surgeons; Joint Section on Neurotrauma and Critical Care, AANS/CNS. Guidelines for the management of severe traumatic brain injury. IX. Cerebral perfusion thresholds. J Neurotrauma 2007;24(Suppl 1):S59-S64

43 Raichle ME, Plum F. Hyperventilation and cerebral blood flow. Stroke 1972;3(5):566-575

44 Coles JP, Minhas PS, Fryer TD, et al. Effect of hyperventilation on cerebral blood flow in traumatic head injury: clinical relevance and monitoring correlates. Crit Care Med 2002;30(9):1950-1959

45 Ropper AH. Management of raised intracranial pressure and hyperosmolar therapy. Pract Neurol 2014;14(3):152-158

46 Shiozaki T, Sugimoto H, Taneda M, et al. Effect of mild hypothermia on uncontrollable intracranial hypertension after severe head injury. J Neurosurg 1993;79(3):363-368

47 Polderman KH, Tjong Tjin Joe R, Peerdeman SM, Vandertop WP, Girbes AR. Effects of therapeutic hypothermia on intracranial pressure and outcome in patients with severe head injury. Intensive Care Med 2002;28(11):1563-1573

48 Chesnut RM, Marshall LF, Klauber MR, et al. The role of secondary brain injury in determining outcome from severe head injury. J Trauma 1993;34(2):216-222

49 Grände PO, Asgeirsson B, Nordström C. Aspects on the cerebral perfusion pressure during therapy of a traumatic head injury. Acta Anaesthesiol Scand Suppl 1997;110:36-40

50 ASHP Therapeutic Guidelines on Stress Ulcer Prophylaxis. ASHP Therapeutic Guidelines on Stress Ulcer Prophylaxis. ASHP Commission on Therapeutics and approved by the ASHP Board of Directors on November 14, 1998. Am J Health Syst Pharm 1999; 56(4):347-379

51 Finfer S, Liu B, Chittock DR, et al; NICE-SUGAR Study Investigators. Hypoglycemia and risk of death in critically ill patients. N Engl J Med 2012;367(12):1108-1118

52 Norwood SH, McAuley CE, Berne JD, et al. Prospective evaluation of the safety of enoxaparin prophylaxis for venous thromboembolism in patients with intracranial hemorrhagic injuries. Arch Surg 2002;137(6):696-701, discussion 701-702 